\title{
SURVIVAL STRATEGIES OF MICROORGANISMS IN EXTREME SALINE ENVIRONMENTS
}

\author{
J. F. Imhoff \\ Institut für Mikrobiologie der Universität Bonn, Meckenheimer Allee 168, D-5300 Bonn, \\ F.R.G.
}

\begin{abstract}
Halophilic representatives are found in all main lines of evolutionary descendence of microbes: in archaebacteria, Gram-negative and Gram-positive eubacteria, and also in eucaryotes. In principe all halophilic microorganisms have to adapt their surface and membrane structures to their highly ionic environments. Concerning their intracellular compartment two different strategies have been developed: Inorganic ions are largely excluded in some microorganisms while such ions are actively accumulated in others. In particular the second group of organisms has to adapt the whole metabolic machinery to the highly ionic conditions of several molar salts, whereas in the first group only the outer surface of the cytoplasmic membrane and the extracytoplasmic structures are in contact with high concentrations of inorganic ions. In this latter group, a variety of organic solutes is accumulated in response to increases of the salinity of the environment.
\end{abstract}

\section{INTRODUCTION}

Host of the aquatic microorganisms that live on earth inhabit freshwater and marine habitats and quite a small number tolerate or even require moderate to high salt concentrations. Those microorganisms that have developed mechanisms to survive and to live in hypersaline and extremely concentrated brines enjoy decreasing competition with other microorganisms because of a decreasing species diversity with increasing salinity. In addition many predators (with the important exception of the brine shrimp Artemia salina) can not survive under these conditions and therefore halophilic bacteria often accunulate in masses in hypersaline brines.

\section{ENVIRONIANTAL FACTORS}

In nature, hypersaline environments are present on all continents, although they are predominant in warial and dry clinatic regions. The major components of the inorganic ions contributing to the total salinity of some representative salt lakes are sunmarised in Table 1. Fron these data it is apparent, that not only the relative proportions of jivalent cations (particularly nagnesium and calcium), but also those of the anions (particularly chloride, sulfate and carbonate) vary to a high degree.

Adaptation and survival of nicroorganisms in these habitats is not only dependent on the total salt concentration, but also on the relative ionic composition of the environtnent. In this respect, it is interesting to see that anong the halobacteria, species have developed that are specifically adapted to the thalassohaline environnent (see /1-3/) or to the Dead Sea with its extraordinary high content of calcium and magnesium ions /4,5/. joth environments have a near neutral pir. The existence of forms specifically adapted to nagnesium and calciun deficient, alkaline environments has been postulated after observations in sone soda lakes in the Vadi ilatrun, Jgyt /6/. Such bacteria have been isolated from these and similar lakes $/ 7-9 /$.

Similar adapted forms nay be found in the algal genus Dunaliella, which lives in the Dead Sea $/ 10 /$, in the Great Salt Lake $/ 11 /$, in alkaline soda lakes $/ 6 /$, and also in narine salterns $/ 12 /$.

ilalophilic Jctothiorhodospira cells, however, appear specifically adapted to alkaline brines and nass developments of these bacteria have not been found in salt lakes with neutral pir. Despite this variation in the relative ionic composition of natural salt lakes, the zeneral problen of all halophilic microorganisms is to successfully deal with high ionic concentrations and high osmotic pressures created by these salt solutions. 


\section{SALT RELATIONS OF HALOPHILIC MICROORGANISMS}

The organisms which occur in extreme saline environments include Gram-negative and Grampositive eubacteria, archaebacteria and even eucaryotic microorganisms like the alga Dunaliella, all of which are on different main lines of microbial evolution that show significant principal physiological and structural differences, such as in the composition of their cell membranes and outer cell layers. Consequently structural adaptation in these different groups is expected to reveal differences, even if similar principal strategies are employed.

The microorganisms most commonly found in many brines include first of all the halobacteria (archaebacteria which perform aerobic respiratory metabolism), the Ectothiorhodospiraceae (Gram-negative phototrophic bacteria living in the anoxic environment of alkaline salt lakes), the alga Dunaliella (an oxygen producing, phototrophic eucaryote without a cell wall), and occasionally the cyanobacterium Spirulina (which forms blooms in some soda 1akes, but is less halophilic than the before mentioned microorganisms). All of these rilicroorganisms have the capacity to transform light energy into metabolically usefull energy, i.e. membrane gradients and ATP. The halobacteria use a light driven proton pump in their purple membrane, while all others have chlorophyll mediated reactions. Probably the coloration of these microorganisms makes their development so conspicuous and therefore, more easily recognized than that of non-colored heterotrophic bacteria which have been found in high numbers in marine salterns of intermediately high salt content, where Dunaliella also reaches the highest cell density /12/.

TABLE 1: Ionic Composition of Different Types of Salt Lakes

\begin{tabular}{|c|c|c|c|c|c|}
\hline & $\begin{array}{l}\text { Great Salt } \\
\text { Lake }\end{array}$ & $\begin{array}{l}\text { Harine } \\
\text { saltern }\end{array}$ & $\begin{array}{c}\text { Soda } \\
\text { Zugin }\end{array}$ & $\begin{array}{l}\text { lakes } \\
\text { Gaar }\end{array}$ & Dead Sea \\
\hline $\mathrm{Na}^{+}$ & 105.4 & 65.4 & 142.0 & 137.0 & 39.2 \\
\hline $\mathrm{x}^{+}$ & 6.7 & 5.2 & 2.3 & 1.4 & 7.3 \\
\hline $\operatorname{lig}^{2+}$ & 11.1 & 20.1 & nd. & nd. & 40.7 \\
\hline $\mathrm{Ca}^{2+}$ & 0.3 & 0.2 & nd. & nd. & 16.9 \\
\hline $\mathrm{Cl}^{-}$ & 181.0 & 144.0 & 154.6 & 173.7 & 212.4 \\
\hline $\mathrm{SO}_{4}{ }^{2-}$ & 27.0 & 19.0 & 22.6 & 48.0 & 0.5 \\
\hline Carbonates & 0.7 & - & 67.2 & 6.6 & 0.2 \\
\hline Total salts & 332.5 & 253.9 & 393.9 & 374.2 & 322.6 \\
\hline $\mathrm{pH}$ & 7.7 & ca. 7 & 11.0 & 10.9 & ca. 6 \\
\hline
\end{tabular}

Concentrations are in $\mathrm{g} / 1$; nd. = not detected; data from $/ 6,13-15 /$.

According to the amount of salt required for optimal growth and to the upper limit of salt concentrations that still allows growth, we distinguish between halophily and halotolerance. Bacteria are classified as non-halophilic with salt optima below $0.2 \mathrm{H} \mathrm{NaCl}$, as slightly halophilic with optima between 0.2 and $1.0-1.2 \mathrm{M} \mathrm{NaCl}$, as moderately halophilic with optima between 1.0 to $2.0-2.5 \mathrm{M} \mathrm{NaCl}$ and as extremely halophilic with optima above $2.5 \mathrm{im}$ ivaCl (which is approximately $15 \%$, see $/ 16 /$ ). The same limits of salt concentrations are used to describe their salt tolerance.

It is obvious from the conparison of their salt optima, that a number of halophilic microorganisms have developed mechanisms to optimally adapt to varying high salt concentrations and are stressed by lowering this salt content. On the one hand, $0.5 \mathrm{~N} \mathrm{IaCl}$ is an extreme salt stress hardly tolerated by the non-halophilic E. coli. On the other hand, Halobacterium cutirubrum and Ectothiorhodospira halophila can barely survive, even if the salt concentration is doubled to about 1 i. NaCl. Therefore, from the point of view of a Halobacterium, extremely high salt concentrations are quite normal and can not be regarded as a stress. This implies that all cellular structures and the whole metabolic machinery are well adapted to the highly ionic conditions and high osmotic pressures of their environments. In the following, different strategies of various microorganisms, in particular of Dunaliella, of halobacteria, and of various halophilic and halotolerant eubacteria, are briefly summarized. 


\section{SURVIVAL MECHANISMS}

The first problem that all halophilic microrganisms have to deal with is the osmotic balance, generally achieved by the accumulation of high internal solute concentrations. Increasing solute concentrations are equivalent to increasing water deficiency. Halophilic bacteria appear optimally adapted to this kind of water stress. Even E. coli, growing in very dilute media maintains a cytoplasmic osmotic pressure that approxinately equals a 300 $\mathrm{mM}$ salt solution /17/, whereas halophilic microorganisms may accunulate several molar concentrations of a single solute. As pointed out by Brown $/ 18,19 /$, it is a precondition for the accumulation of high solute concentrations within the cell that these solutes have to be compatible with cellular structures and physiological processes, i.e. they must not destroy protein and membrane structures and must be less inhibitory to enzymatic reactions than other solutes. Brown called these solutes "compatible solutes". A number of different compatible solutes is accumulated by various microorganisms (see below).

The second problem that faces extremely halophilic microorganisms is the structural and functional integrity of the cell membranes and outer layers that, in contrast to the cytoplasmic compartment, are in direct contact with the highly ionic environment. It is this part of the cell that mediates exchange of substrates and metabolic products between cytoplasm and external environment, catalyzes the built up and maintenance of high solute gradients, serves the energy generation of the cell, and gives the cell its structural rigidity.

\section{The Alga Dunaliella}

Dunaliella is the dominant primary producer of the northern part of Great Salt Lake (where the salt concentration reaches saturation) $/ 11 /$, of the Dead Sea $/ 10 /$, of Lake Gaar in the Wadi Natrun /6/, and also occurs in great numbers in ponds of marine salterns with intermediately high salt concentrations /12/. Dunaliella quite effectively excludes inorganic ions from the cells and accumulates for osmotic compensation high concentrations of glycerol. In $D$. viridis growing at $4.25 \mathrm{M} \mathrm{NaCl}$, glycerol is accumulated to a concentration of 4.4 molal 720/. Accumulation of glycerol is possible by photosynthesis as well as from accumulated starch in the dark. Dunaliella is able to quite effectively regulate its glycerol content in response to the external salt concentration. A glycerol cycle has been proposed to occur in this alga /21/ that involves formation of glycerol from dihydroxyacetone phosphate via glycerol-3-phosphate and degradation of glycerol to dihydroxyacetone and dihydroxyacetone phosphate, which than can be osmotically inactivated by conversion into storage carbohydrate. Evidence accumulates that both processes are spatially separated. The key step of the biosynthetic pathway is mediated by 3lycerol-3-phosphate dehydrogenase localized in the chloroplast, whereas the key step of its degradation is catalyzed by glycerol dehydrogenase localized in the cytoplasm /22,23/. This separation makes sense, as the required energy and photosynthetate is provided by the light metabolisin in the chloroplast, whereas under conditions of decreased osmolarity, glycerol accumulated in the cytoplasm has to be removed rapidly from this compartment.

Little is known about the structural adaptation of this alga. In particular, the structural basis of the imperneability of the cytoplasmic membrane to glycerol, which is freely permeable through other biological membranes, needs to be studied.

\section{The Halobacteria}

Dominating types of heterotrophic bacteria in Great Salt Lake, Dead Sea, African soda lakes, and concentrated pools of marine salterns are various species of extremely halophilic bacteria (halobacteria) of the genera Halobacterium, Halococcus, Natronobacterium, Natronococcus, and Haloarcula. Halobacteria are without doubt the organisms which are best adapted to the life in the extremes of concentrated salt solutions. (The extremely halophilic species of Ectothiorhodospira are dependent on anoxic conditions.) In contrast to other halophilic microorganisms, their cytoplasm is highly ionic and $\mathrm{KCl}_{\mathrm{C}}$ is the main compatible solute. Potassium concentration exceeding $5 \mathrm{M}$ and sodium concentrations in the molar range have been reported $/ 1,24-26 /$. The total internal concentration of monovalent cations even exceeds the external one.

Proteins. Hany enzymatic reactions are dependent on high potassiun concentrations and also tolerate high concentrations of $\mathrm{NaCl} / 2,24,27 /$. One striking feature of halobacterial proteins is their highly acidic nature and it was argued, that high ion concentrations are required for neutralization of the protein charges to keep them in a metabolically active configuration. Charge shielding should, however, be effectively completed at monovalent cation concentrations well below $1 \mathrm{il}$, as has been pointed out by Lanyi /27/, whereas many halophilic enzymes require much higher concentrations for activity and stability. It was proposed that the high salt demand of these proteins is not only neccessary for charge shielding, but that their stability depends on conditions where hydrophobic interactions are increased by high concentrations of $\mathrm{NaCl}$ or $\mathrm{KCl} / 27 /$. 
Cell envelope. Structural integrity of the cell envelope of Halobacterium cutirubrum is extrenely sensitive to the ionic strength of the medium. When celis are suspended in successively lower $\mathrm{HaCl}$ concentrations, they change from rods to spheres and lyse at about 1.0 to $1.5 \mathrm{iNaCl}$ (see /25/). Disintegration of the cell membrane occurred at somewhat lower $\mathrm{NaCl}$ concentrations below $\mathrm{I} \mathrm{H}$ and could be prevented by $20 \mathrm{mM}$ magnesium even in the complete absence of $\mathrm{NaCl} / 23 /$. The major component of the cell wall of $\mathrm{H}$. salinarium is a glycoprotein of high molecular weight and it was suggested that the carbohydrate moiety of this glycoprotein is essential for maintenance of the cell shape /29/.

Lipids. About $2-4 \%$ of the cell dry weight in $\mathrm{H}$. cutirubrum are lipids. The polar lipids of these bacteria, consisting of phospholipids and glycolipids, compose about $90 \%$ of the total lipids. These polar lipids are derivatives of a glycerol diether, and usually have phytanyl groups as hydrocarbon chains $19,30,31 /$. In alkaliphilic halobacteria $\mathrm{C}_{20} \mathrm{C}_{25}$ and $\mathrm{C}_{25} \mathrm{C}_{25} \mathrm{di-}$ ether core lipids have also been found $19,31 \%$. The major lipids of $\mathrm{H}$. ${ }^{2}$ cutirubrum are diphytanyl glycerol ether analogs of phosphatidylglycerophosphate, phosphatidylglycerol, and phosphatidylglycerosulfate. In addition to these phospholipids several halobacteria have glycolipids, in particular unusual sulfated glycolipids. The neutral lipids consist mostly of squalene, dihydro- and tetrahydrosqualene, $\mathrm{K}-8$, diphytanol glycerol ether, and various pigments /32-34/. At neutral pH, a lipid such as phosphatidylglycerophosphate is a dianion with each phosphate group singly ionized $/ 35 \%$. It was pointed out that in a bilayer structure, one of these phosphate groups will be at the aqueous surface, whereas the other will be in the bilayer structure and therefore less accessible to water and cations /36/. Fron their observations, these authors proposed that magnesium ions can form bridges to the outer charged headgroups of the polar lipids only if sufficient neutral lipid like squalene is present to space the phospholipids far enough apart to allow cations to approach the negatively charged groups. The active participation of protein would also be necessary for the stability of such bilayers. The stability of the membrane bilayer of the classical halobacteria at high salt concentrations seems therefore to depend on the combination of their polar lipids, neutral lipids, bivalent cations, and proteins. The participation of bivalent cations in nembrane stabilization is, however, unlikely in the alkaliphilic halobacteria (species of Natronococcus and Natronobacter) which are adapted to environments deficient in those cations. These bacteria grow well at 0.1-2.0 mil magnesium and are inhibited at higher concentrations $/ 7,8 /$. It is necessary to assume that either monovalent cations replace the function of bivalent cations or that negative charges are screened by organic molecules in these bacteria.

\section{The Halophilic Eubacteria}

Proteins. The high acididity of proteins in halobacteria has been explained as an adaptative mechanisms towards their high content of ions in the cytoplasm. Since inorganic ions are largely excluded from the cytoplasm of halophilic eubacteria (see below), one would predict that soluble proteins of these bacteria are much less acidic. Membrane proteins, however, which have one side exposed to to the highly ionic environment, should have an acidity intermediate between those proteins of halobacteria and of non-halophilic bacteria. An analysis of membrane proteins of several Ectothiorhodospira strains with different optimal salinities revealed an increasing anount of polar and intermediate annino acid residues, concomittant with a decrease of apolar residues, in proportion to their increasing salt requirement $/ 37 /$. The results with whole cell proteins did not show this clear correlation. As discussed by Lanyi /27/ the intermediate amino acid residues are thought responsible for the stability of halophilic enzymes at high salt concentrations.

It was shown recently, that whole cells of the anaerobic halophilic bacteria laloanaerobium praevalens, Halobacteroides halobius, and Clostridium lortetii, contain proportions of polar amino acids more similar to Halobacterium than to E. coli cells and have an excess of acidic

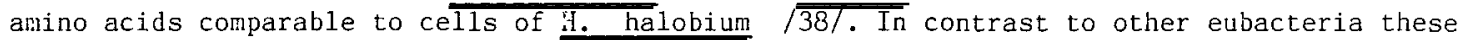
anaerobes have high cytoplasmic concentrations of inorganic ions /38/. As "normal proteins" would not be stable under these conditions, these bacteria have acidic proteins. Thus a general relation between the amino acid composition of proteins and the ion concentration in their surrounding microenvironment seems to be realized in archaebacteria as well as in certain eubacteria.

Cell envelope. Little information is available on the influence of high salt concentrations on structures of the cell envelope in halophilic eubacteria. In the Gran-negative, nonhalophilic $\mathrm{E}$. Coli, however, detailed genetic studies have revealed, that the conposition of the outer meinbrane is subject to osmotic regulation (see /16/). The biosynthesis of outer meinbrane proteins encoded by ompC and ompF in $\mathrm{E}$. coli is strikingly affected by the osinolarity of the medium and ompC is preferentially expressed at high osmolarity while onp is is preferentially expressed at low osmolarity. A third locus, the ompt operon has been identified as a regulator region for both ompC and onpF that encodes two genes, ompR and envZ. A general role of EnvZ as an osmosensor is suggested by findings that mutations affecting transcription of lablj and ma1E map identical with envZ mutations, and that mutations in envZ also reduce the production of a periplastaic alkaline phosphatase and several iron-induced 
outer membrane proteins /39-41/. A further gene, micF, is involved in the regulation of the onpF expression /42/. Results indicate the coregulation of micF with ompC in a way that micF acts to repress ompF under conditions favorable for ompC expression, i.e. at high osmolarity /43/. Similar osmotically regulated structural changes have so far not been observed in halophilic eubacteria, although one has to predict that adaptative changes occur.

Lipids. It is evident that both moderately and extremely halophilic eubacteria have the capacity to regulate the composition of their membranes in regard to lipid head groups and fatty acids in response to the salinity of their surrounding environment. A general tendency in representatives of Gram-negative and Gram-positive eubacteria is an increase of negatively charged phospholipids with increasing salinity. In particular a decrease in the relative content of phosphatidylethanolamine was found in some bacteria, while the relative contents of phosphatidylglycerol and/or cardiolipin increased /44-47/.

Osmotic adaptation. A great variety of solutes is used within different eubacteria to achieve osmotic balance with the external environment. The ions outside the cell in most cases strongly inhibit enzymatic processes in the cytoplasin and accurulated substances generally differ from the major solutes outside the cells. In eubacteria, accumulation of high concentrations of inorganic ions, but not of organic solutes has been observed only in some anaerobes by Oren $/ 38 \%$. In most of the halophilic eubacteria, various organic solutes are accumulated. The kind of solute accumulated depends on growth conditions (in particular the osmolarity of the growth medium) and, to the major part, on the bacteriun. The major solute accunulated seems to be one important factor determining the degree of salt stress tolerated by the respective bacteriun $/ 16,48 /$. For some of these solutes, which were found as the major compatible solutes only in non-halophilic and slightly halophilic bacteria, their solubility and/or toxicity restrict accumulation in high concentrations. The solutes which predominate in halophilic, and halotolerant eubacteria are listed below:

i) Jon-halophilic and slightly halophilic eubacteria accumulate glutamate, proline, a few other amino acids, potassium, and several sugars (sucrose, fructose, glucose, trehalose).

ii) Hoderately and extremely halophilic and halotolerant eubacteria accumulate as major components glycine betaine or glutamate betaine, glucosylglycerol, in some cases also ectoine, and one or more minor components (glutamate, potassium, trehalose, sucrose).

This accumulation is either achieved by biosynthesis or by uptake from the mediuin. There is evidence that the presence of complex nutrients or other specific compounds, that can be taken up and accumulated by the bacteria, increase their salt tolerance (see /16/). This indicates, that accuraulation of compatible solutes may be one limiting factor of the salt tolerance. liost of the information available on osmoregulatory responses and compatible solute accumulation is on non-halophilic and slightly halophilic eubacteria and far less on moderately and extremely halophilic eubacteria. (This topic has recently been reviewed $/ 16 /$.

In a number of non-halophilic and slightly halophilic eubacteria potassiun is accumulated under conditions of osmotic stress. In T. coli two transport systems for potassium are regulated by the external osinolarity or the turgor pressure, such as the Trk- and the kidpsystems. The Kdp-system is in addition regulated on the genetic level, i.e. it is induced by decreasing the turgor pressure.

Glutamic acid is, under normal conditions, one of the major amino acids in the cellular anino acid pool of bacteria. The proportion of glutamic acid to the total cellular free amino acid pool is normally about 50\%, but may increase, up to more than $90 \%$ under salt stress conditions. Its concentration is dependent on the osmolarity of the growth conditions in a number of slightly and moderately halophilic bacteria and it can be accumulated by biosynthesis. As an anion its accumulation is dependent on the presence of equivalent concentrations of cations in the cytoplasm. It has also been shown that uptake of potassium and glutanic acid (or other weak acids) stimulate each other, and are in turn stimulated by the osmolarity of the medium. It is reasonable to assume that potassium to a great part neutralizes the charges of glutamic acid.

Proline is a very soluble and suitable compatible solute that is, under normal conditions, present in the cytoplasil only in very minor amounts and whose biosynthesis is strictly feedback inhibited in tuany bacteria. Proline accumulation by biosynthesis has been shown in Bacillus subtilis var. nizer and in Streptonyces griseus. ilost of the other bacteria depend on active uptake systeins for accunulation of proline. In E. coli, proline is taken up from the medium by several transport systems, two of which are activated by osmotic stress. If proline is present in the media these bacteria preferably accumulate this arino acid instead of glutamate and potassiun. 
Glycine betaine is the major compatible solute in many moderately and extremely halophilic eubacteria /48-51/. The first evidence for biosynthesis of glycine betaine in bacteria was obtained by Galinski and Truper /49/. They studied the halophilic Ectothiorhodospira halochloris which accumulates this solute in concentrations exceeding $2 \%$. Betaine has been shown by gas chromatographic analysis and by ${ }^{13} \mathrm{C}$-IMM techniques to be one of the major solutes in a number of moderately halophilic eubacteria, that accumulate betaine in dependence on the salinity of growth conditions /48/. Even in E. coli, osmotically activated transport systems that catalyze the accumulation of glycine betaine have been described recently. The function of these transport systems is currently under debate. They do not seem to be strictly specific for betaine or proline, but their catalyzed reaction is apparently dependent on experimental conditions. Two independent transport systems have been described as osmotically induced proline transport systems, but later shown to prefer glycine betaine as the substrate.

These findings and the fact that a number of soluble proteins of these bacteria are severely inhibited by even low salt concentrations, makes it very likely that the cytoplasm of moderately and extremely halophilic eubacteria is not highly ionic. This is in contrast to the situation in the extremely halophilic archaebacteria, that accumulate high internal potassium concentrations and have soluble proteins and a protein synthesizing machinery that is structurally adapted to the high ionic content of the cytoplasm. A similar adaptation of the cytoplasmic components to highly ionic conditions, however, has to be expected in those halophilic anaerobes that lack organic compatible solutes and that have a highly ionic cytoplasm, such as Haloanaerobium, Halobacteroides, and Clostridium lortetii $/ 38 /$.

\section{CONCLUSION}

As we have seen, different approaches have been developed for adaptation to high salt concentrations. In halobacteria and also in a few eubacteria the cytoplasm is highly ionic and potassium is the predominant cytoplasmic cation. In most of the eubacteria, and in the alga Dunaliella, however, the external ions are largely excluded and organic solutes are accumulated either by uptake or by biosynthesis. In both cases the function of physiological processes within the cytoplasn seems to be adapted to high concentrations of the solute accumulated. Apparently one general strategy is the increase of negative charges at the surface of molecules (lipids and proteins) exposed to highly ionic solutions.

There are, however, a number of unanswered crucial questions. We know nothing about the signals that trigger adaptation processes following salt stress, nor do we know how this signal is transformed into the adaptive processes. The structural and/or functional properties that determine the observed salt optima in various halophilic bacteria are also unknown. It is unlikely that accumulation of sufficiently high concentrations of suitable conpatible solutes determines the halophilic property of a bacterium. There are several known cases were accumulation of compatible solutes proceeds towards salt concentrations higher than optinal and where solute accumulation is one of the factors determining the upper limit of growth rather than the optimum (see /16/). A crucial point in this respect may be found in structural and functional adaptation of membrane and envelope components. Our present knowledge, however, does not allow any clear conclusions.

\section{REFERENCES}

1. i. Larsen, Adv. liicrobiol. Physiol. 1, 97 (1967)

2. D.J. Kushner, in: Hicrobial life in extreme environments, ed. D.J. Kushner, Acadenic Press, 1978, chapter 8 .

3. F. Rodriguez-Valera, G. Juez, and D.J. Kushner, System. Appl. Microbiol. 4, 369 (1983)

4. M.F. Mullakhanbhai and H. Larsen, Arch. Microbiol. 104, 207 (1975)

5. S. Cohen, A. Oren, and M. Shilo, Arch. Hicrobiol. 136, 184 (1983)

6. J.F. Inhoff, H1.G. Sahl, G.S.it. Soliman, and H.G. Trüper, Geomicrobiol. J. 1, 219 (1979)

7. G.S.H. Soliman and H.G. Trüper, Zbl. Bakt. Hyz. I Abt. Orig. C3, 318 (1982)

3. B.J. Tindall, A.A. liills, and H.D. Grant, J. Gen. Hicrobiol. 116, 257 (1980)

9. B.J. Tindall, H.iv.i3. Ross, and U.D. Grant, Systen. Appl. Hlicrobiol. 5, 318 (1934)

10. B.E. Volcani, Doctoral thesis, Hebrew University, Jerusalem (1940)

11. T.D. Brock, J. Gen. Hicrobiol. 89, 285 (1975) 
12. F. Rodriguez-Valera, A. Ventosa, G. Juez, and J.F. Imhoff, Microbiol. Ecol. 11, 107 (1985)

13. F.J. Post, Microbial Ecol. 3, 143 (1977)

14. A. Nissenbaum, Microbial Ecol. 2, 139 (1975)

15. S. Nixon, Doctoral thesis, University of North Carolina, Chap Hill, Horth Carolina (1970)

16. J.F. Imhoff, FElS Ificrobiol. Rev. 39, 57 (1986)

17. J.B. Stock, B. Rauch, and S. Roseman, J. Biol. Chem. 252, 7850 (1977)

18. A.D. Brown, Bacterio1. Rev. 40, 803 (1976)

19. A.D. Brown, Adv. Hicrobiol. Physiol. 17, 181 (1978)

20. L.J. Borowitzka and A.D. Brown, Arch. Hicrobiol. 96, 37 (1974)

21. K. Wegmann, Ber. Deutsch. Bot. Ges. 92, 43 (1979)

22. A.D. Brown, R. H.l.C. Lilley, and T. Vlarengo, Z. Naturforsch. 37c, 1115 (1982)

23. H. Gimmler and G. Lotter, Z. Naturforsch. 37c, 1107 (1982)

24. I.E.D. Dundas, Adv. Microbiol. Physiol. 15, 85 (1977)

25. S.T. Bayley and R.A. Morton, CRC Critical Rev. Microbiol. 6, 151 (1978)

26. J.K. Lanyi, Microbio1. Rev. 42, 682 (1978)

27. J.K. Lanyi, Bacteriol. Rev. 38, 272 (1974)

28. A.E. Blaurock, W. Stoeckenius, D. Oesterhelt, and G.L. Scherphof, J. Cell Biol. 71, 1 (1976)

29. M.F. Mescher and J.L. Strominger, Proc. Natl. Acad. Sci. U.S.A. 73, 2687 (1976)

30. M. Kates and S.C. Kushwaha, in: Lipids, eds. R. Paoletti, G. Porcellati, and G. Jacini, Raven Press, New York, 1976, Vol. 1, p. 267.

31. M. DeRosa, A. Gambacorta, B. Hicolaus, and W.D. Grant, J. Gen. Hicrobiol. 129, 2333 (1983)

32. T.G. Tornabene, H. Kates, E. Gelpi, and J. Oro, J. Lipid Res. 10, 294 (1969)

33. S.C. Kushwaha, E.L. Pugh, J.K.G. Kramer, and M. Kates, Biochira. Biophys. Acta 260, 492 (1972)

34. S.C. Kushwaha, G. Juez-Perez, F. Rodriguez-Valera, W. Kates, and D.J. Kushner, Can. J. Microbiol. 28, 1365 (1982)

35. M. Kates, L.S. Yengoyan, and P.S. Sastry, Biochin. Biophys. Acta 98, 252 (1965)

36. J. K. Lanyi, W.Z. Plachy, and Ii. Kates, Biochen. 13, 4914 (1974)

37. J.F. Imhoff, D.J. Kushner, and P.J. Anderson, Can. J. Microbiol. 29, 1675 (1983)

38. A. Oren, Can. J. Microbiol. 32, 4, (1986)

39. C. Wandersinan, F. Moreno, and M. Schwartz, J. Bacteriol. 1374 (1980)

40. B.L. Wanner, A. Sarthy, and J. Beckwith, J. Bacteriol. 140, 229 (1979)

41. B.L. Wanner and P. Latterell, Genetics 96,353 (1930)

42. T. Hizuno, M.-Y. Chou, and H. Inouye, Proc. Nat1. Acad. Sci. U.S.A. 31, 1966 (1983)

43. C.A. Schnaitman and G.A. ifcDonald, J. Bacteriol. 159, 555 (1984)

44. H. Kogut and if.J. Russe1, Curr. liicrobiol. 10, 95 (1984) 
45. K.J. Killer, J. Bacteriol. 162, 263 (1985)

46. H. Hara and i1. Masui, FEMS Microbiol. Lett. 31, 279 (1985)

47. J.F. Imhoff, unpublished data

48. J.F. Imhoff and F. Rodriguez-Valera, J. Bacteriol. 160, 478 (1985)

49. E. Galinski and H.G. Trüper, FEIS Microbiol. Lett. 13, 357 (1932)

50. R.H. Reed, D.L. Richardson, S.R.C. Warr, and W.D.P. Stewart, J. Gen. Microbiol. 130, I (1984)

51. M.A. Mackay, R.S. Norton, and L.J. Borowitzka, J. Gen. Microbiol. 130, 2177 (1984) 